\title{
Rare cause of asymptomatic giant hydronephrosis
}

\author{
Anna Pokrovskaya, Maria Vetluzhskaya, Uliana Bazhanova, Valery Podzolkov
}

Department of Faculty Therapy \#2, I M Sechenov First Moscow State Medical University (Sechenov University), Moscow, Russian Federation

\section{Correspondence to}

Dr Maria Vetluzhskaya; maria.vetluzhskaya@gmail.com

Accepted 7 March 2021

D) Check for updates

(c) BMJ Publishing Group Limited 2021. No commercial re-use. See rights and permissions. Published by BMJ.

\begin{tabular}{l}
\hline To cite: Pokrovskaya A, \\
Vetluzhskaya M, \\
Bazhanova U, et al. BMJ \\
Case Rep 2021;14:e241357. \\
doi:10.1136/bcr-2020- \\
241357 \\
\hline
\end{tabular}

\section{DESCRIPTION}

A 40-year-old patient presented to the clinic with a months history of symptoms related to upper gastrointestinal problem. He had no problems with urination, there were single episode of nocturnal diuresis. He never had any hypertension or medical problem before. His previous history and social history were unremarkable. On examination his general condition was good. His blood pressure was $130 / 80 \mathrm{~mm} \mathrm{Hg}$ and pulse was 74 beats/min. Abdominal examination revealed any clinical sign of gastro-oesophageal reflux. There was no costovertebral angle tenderness.

Clinical and biochemical blood test includes urinalysis were normal. His glomerular filtration rate (GFR) was $87.83 \mathrm{~mL} / \mathrm{min} / 1.73 \mathrm{~m}^{2}$. He had esophagogastroduodenoscopy which showed signs of gastro-oesophageal reflux disease and chronic gastritis. Abdominal ultrasound showed incidental findings of significant dilatation of the collecting system on the left side. This finding was further investigated using more detailed imaging. Abdominal CT with intravenous contrast enhancement was conducted (figure 1). Conclusion: grade III hydronephrosis on the left at the background of uteropelvic junction (UPJ) stenosis with probable conflict of the additional renal artery and the lower segmental vein. Renal scintiangiography: renal haemodynamics parameters are normal. The secretory and excretory functions of the right kidney are not impaired. On the left-reduction in the volume of functioning parenchyma with mixed-type excretory functions inhibition with the presence of parenchymal and, mainly, obstructive components. The patient underwent surgery: laparoscopic left UPJ plasty. A temporary stent was inserted in the left ureter. Biopsy material investigation-microscopic signs correspond to the UPJ stenosis. One month after the surgery, the control ultrasound showed dilation of the collecting system on both sides. There was no residual urine. Given the positive changes showed by ultrasound, renal CT with contrast was not performed. Follow-up blood tests and urine analyses remain within normal limits. The treatment prescribed by the gastroenterologist had a quick positive effect.

Hydronephrosis is a persistent and progressively increasing expansion of the collecting system, accompanied by urine retention due to the outflow obstruction. The most frequent causes are congenital abnormalities. ${ }^{1}$ Acquired causes include urolithiasis, strictures due to postoperative or inflammatory changes, adhesions, polyps and malignant neoplasms. Aberrant renal artery is a rare cause of hydronephrosis in adults. Aberrant renal artery to the inferior pole crosses the anterior UPJ in $6.8 \%$ of cases. In very rare cases, it passes so close
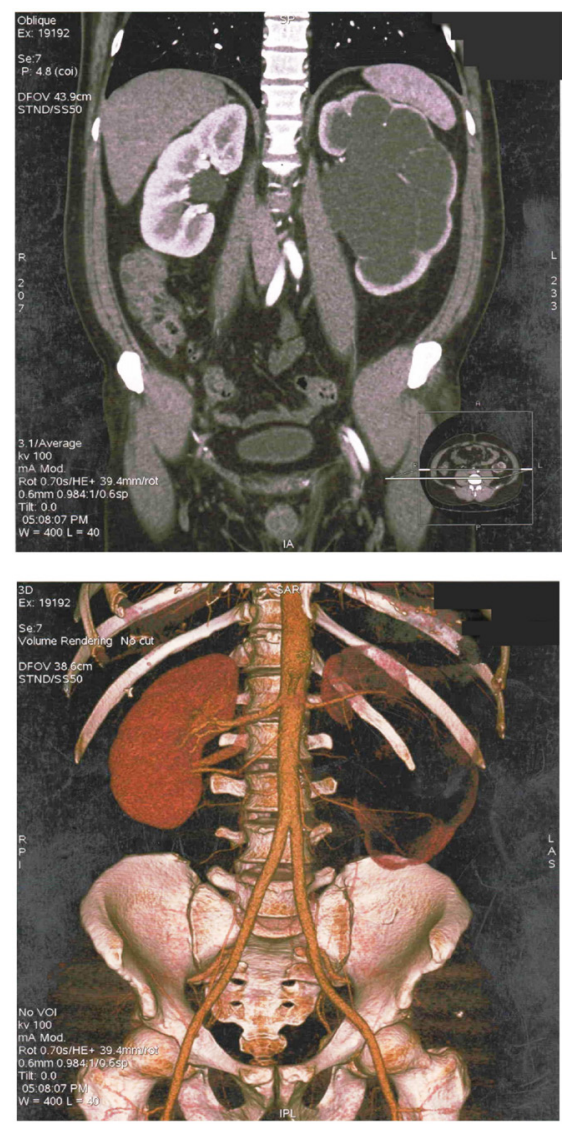

Figure 1 Abdominal CT with intravenous contrast enhancement signs of grade III hydronephrosis on the left at the background of ureteropelvic junction stenosis with probable conflict of the addition renal artery and the lower segmental vein. Collecting cavities are dilated, calyces - up to $52 \mathrm{~mm}$, mixed-type pelvis, $97 \times 88 \times 99 \mathrm{~mm}$. Ureteropelvic segment is narrowed. Two renal arteries were noted, the main artery originates from the aorta at the level of $\mathrm{L} 1$ ( $6 \mathrm{~mm}$ in diameter), the addition artery originates from the aorta at the level of $\mathrm{L} 2(4 \mathrm{~mm}$ in diameter). The renal vein is $16 \mathrm{~mm}$ in diameter. The addition artery, together with the inferior segmental renal vein, crosses the ureteropelvic segment. The excretory function is reduced: only traces of contrast appeared in the calyx over $120 \mathrm{~min}$.

to the UPJ that it provokes the development of hydronephrosis. ${ }^{2}$ In some cases, an aberrant renal artery was found passing behind the ureter. ${ }^{3}$

The most frequent symptoms of hydronephrosis are: intermittent abdominal or flank pain, nausea, vomiting, dysuria and haematuria. ${ }^{1}$ As a rule, hydronephrosis has a progressive course, which contributes to an increase in the dilation of the segments of upper urinary tract and can lead to acute kidney damage, and in the absence of proper 
treatment-to its irreversible loss. ${ }^{4}$ The presence of more than $1000 \mathrm{~mL}$ of fluid in the collecting system of an adult indicates the giant hydronephrosis. This condition largely worsens the prognosis, as it leads to more significant damage to the kidney, in some cases resulting in kidney resection. ${ }^{5}$ Kidney ultrasound is recommended as a screening for hydronephrosis. More detailed information about the upper segments of the urinary tract can be obtained using kidney CT with contrast enhancement. ${ }^{4}$ Outcomes in patients with hydronephrosis due to additional renal artery significantly depend on early diagnosis and appropriate surgical interventions, including ureteric stenting (successfully performed in this case) or laparoscopic

\section{Learning points}

- Hydronephrosis can be asymptomatic with normal blood test parameters and urinalysis.

- This condition is easily diagnosed with the use of ultrasound. Detailed imaging technique is required to investigate the cause.

- Additional renal artery can be one of the causes of hydronephrosis.

- Early surgical interventions can prevent impairment of kidney function and improve patient's prognosis. dismembered pyeloplasty with the pelviureteric anastomosis being placed anterior to the additional vessel.

The clinician should be aware that congenital vascular abnormalities can provoke the development of hydronephrosis not only in newborns, but also in middle-aged individuals, and that this pathology can be asymptomatic.

Twitter Anna Pokrovskaya @Anna Pokrovskaya

Contributors MV, AP, UB, VP participated in data collection, interpretation, article concept planning. AP participated in the writing of the manuscript. VP participated in the editing the manuscript. All authors have read the final version of the manuscript and agree to publication.

Funding The authors have not declared a specific grant for this research from any funding agency in the public, commercial or not-for-profit sectors.

Competing interests None declared.

Patient consent for publication Obtained.

Provenance and peer review Not commissioned; externally peer reviewed.

\section{REFERENCES}

1 Krajewski W, Wojciechowska J, Dembowski J, et al. Hydronephrosis in the course of ureteropelvic junction obstruction: an underestimated problem? current opinions on the pathogenesis, diagnosis and treatment. Adv Clin Exp Med 2017;26:857-64.

2 Park BS, Jeong TK, Ma SK, et al. Hydronephrosis by an aberrant renal artery: a case report. Korean J Intern Med 2003;18:57-60.

3 Parimala NBS. Bilateral aberrant renal arteries with abnormal left renal vein: a case report. J Clin Diagn Res 2013;7:1425-6.

4 Patel K, Batura D. An overview of hydronephrosis in adults. Br J Hosp Med 2020;81:1-8.

5 Budigi B, Dyer RB. "Giant" hydronephrosis. Abdom Radiol 2019;44:1946-8.

Copyright 2021 BMJ Publishing Group. All rights reserved. For permission to reuse any of this content visit https://www.bmj.com/company/products-services/rights-and-licensing/permissions/

BMJ Case Report Fellows may re-use this article for personal use and teaching without any further permission.

Become a Fellow of BMJ Case Reports today and you can:

- Submit as many cases as you like

- Enjoy fast sympathetic peer review and rapid publication of accepted articles

- Access all the published articles

Re-use any of the published material for personal use and teaching without further permission

Customer Service

If you have any further queries about your subscription, please contact our customer services team on +44 (0) 2071111105 or via email at support@bmj.com.

Visit casereports.bmj.com for more articles like this and to become a Fellow 